\section{$\angle$ Research Square}

Preprints are preliminary reports that have not undergone peer review.

They should not be considered conclusive, used to inform clinical practice, or referenced by the media as validated information.

\title{
The Effectiveness of applying for Formative Assessment Objective Structured Clinical Examination (OSCE)for Undergraduate Students in Faculty of Medicine King Abdul Aziz University, Jeddah, Kingdom of Saudi Arabia
}

\author{
Rajaa Allhiani ( $\nabla$ rallhiani@gmail.com ) \\ king Abdulziz University \\ Sumaiah Abdulwahab ( $\nabla$ sumaiahw@gmail.com ) \\ University of Jeddah \\ Sultan Hassan Alamri ( $\square$ shalamri1@kau.edu.sa) \\ King Abdulaziz University
}

Research Article

Keywords: OSCE, formative Assessment, Clinical, Undergraduate medical.

Posted Date: June 4th, 2020

DOI: https://doi.org/10.21203/rs.3.rs-32260/v1

License: (ㄷ) (1) This work is licensed under a Creative Commons Attribution 4.0 International License. Read Full License 


\section{Abstract}

The use of formative and summative assessment for students have been always a concern for medical professionals such as teachers and students especially when students are at graduating level. This can be supported with increasing the effectiveness and comprehensiveness of the students with appropriate clinical training using a defined structure with questionnaire-based system defined in the methodology to support student's skills using clinical competencies to form perspective. It has been found that with Objective Structured Clinical Examination can be used as the method to assess the adequacy to support clinical skills of medical students following their competence level. This can be used to support a variety of tests to work on underpinning emergency procedures to interpret investigational data to ensure in-depth and breadth coverage of clinical skills following $5^{\text {th }}$ year medical students.

\section{Background}

Eight [8] This study of monitoring the effectiveness of the formative OSCE conducted over five years from 2014 until 2018 and still monitoring is going on for 2019. The OSCE is a form of performance-based testing used to measure candidates' specific clinical competencies. nine[9] As the OSCE developed throughout the years, there was a debate about its applicability as an assessment tool especially in terms of its validity and reliability.

Therefore, this study aims to determine the effectiveness of applying formative assessment Objective Structured Clinical Examination (OSCE) for undergraduate 5th year medical students in clinical module. The clinical module took the initiative in applying the formative (OSCE) and had invited residents to participate and practice their assessment skills.Also to measure the effectiveness of Self Direct Learning (SDL) sessions.

\section{Objectives}

Following the purpose of the study, the researcher has put together the key objectives for further research to be considered while collecting and analysing data for this subjective theme. It has been found that two types of assessment are undertaken in educational institutions - summative and formative to evaluate the student's learning progress and give them concrete grades to improve their learning behavior. The objective is to determine the effectiveness of applying formative assessment objective structured clinical examination (OSCE) for the undergraduate $5^{\text {th }}$-year medical students in clinical module. The initiative was applied for the formative OSCE had invited residents to participate and practice their assessment skills to measure the effectiveness of Self Direct learning (SDL) session. The objectives include,

1) To test the effectiveness of formative assessment (OSCE) for undergraduate students

2) To determine the acceptability of the formative (OSCE) since it's not compulsory

3)To identify the strengths and weaknesses of the formative (OSCE) on undergraduate students.

\section{Methods}

Check list of ten (10) questions survey (questionnaire) were distributed to all undergraduate medical students who had participated in the formative (OSCE) to measure their competency and proficiency [4]. In the clinical skills and simulation center (CSSC), the twelve rooms were set up for the formative OSCE. Since there were three identical panels of rooms, so six rooms assigned for inactive stations that contained instructions how to answer the questions and other had X-ray films to diagnose. The other six rooms were active stations that contained standardized patients (SP) and Manikins. The formative OSCE lasted for full day and residents were involved as examiners. This method was applied in 2014 and sustained until 2016. In 2018, this method amended to accept more challenges in inviting house officers (interns) to be the standardized patients (SP) examiners two [2]. Since most of the Interns who are participating in the formative OSCE have finished their rotations in all the clinical departments and were retained in the stations.

\section{Results}

The analyses were done thru cross tabulation by (NCSS) similar to SPSS version 20 of all the survey, and the data was summarized in the following table (Fig.1).

In 2014, the number of students was 208 (95 males\& 113 females) who participated in the formative assessment who all of them reported not enough time since the allotted time for each station of formative (OSCE) was 5 minutes, it should more than 10 minutes. About Eighteen (18) were incomplete questionnaire nothing to report. Ninety (90) of the students reported that it was helpful in highlighting area of weaknesses in their clinical skills and Hundred (100) felt safe to make errors without accountability and confidentiality. Nevertheless, students had reported difficulty with the residents; they had not enough experience to provide feedback and debriefing since they were not involved in their teaching plane (Fig.2). Residents should be involved in teaching undergraduate to practice their teaching skills [2] 
In 2015 and 2016, about half of the students did not participate in the formative assessment OSCE since it was not compulsory (Fig.3). According to adult learning theory, there are several key differences to consider with applying formative OSCE: One (1) Adults are self-regulated meaning that they will decide on what and when they want to learn. Two (2) Adult learners are intrinsically motivated, often by their self-efficacy or their belief in their ability to complete a task, when their feelings of competence and their psychological safety Three (3) Adults use analogical reasoning in learning and practice [7].

In 2017, after observing the withdraw of students from participating in formative OSCE, corrective actions were taken by conducting workshops of orientation and pre-briefing, set ground rules and clarified the expectations of the Formative OSCE to all the students. After participation in the formative assessment, Ninety-nine percent (99\%). they were motivated after allowing enough time for each station where they can learn (Fig.4).

In 2018, we have accepted more challenges in inviting house officers (interns) to be examiners Two [2]. Sixty-nine percent ( $96 \%$ ) they had faced this challenge by accepting interns as their peers who had assisted them in learning and in overcoming their weakness (Fig.5). All the incomplete surveys were discarded and omitted from the analysis.

\section{Conclusion}

The formative assessment is powerful tools had assisted $5^{\text {th }}$ year medical students' in learning and to overcome their weakness. Their feedback was in favor of having formative (OSCE) more often in clinical skills module, which gave them the opportunity to improvement and prepare them for the summative (OSCE), as result repetition and re-sit of this module was reduced. Also suggested that residents should be involved in teaching their curriculum to be familiar with students' syllabus.

The faculty members had diversity of opinion about formative OSCE overseen as time consuming, budget consumption and lack of incentive; on the other hand, students expressed high satisfaction with this type of assessment and their outcome after participating was found remarkably outstanding.

\section{Take Home Messages}

1. OSCE is an effective and widely used method of assessment around the world, but in some places, according to the students, it is not as much as expected to be.

2. OSCE exam, and the way of introducing it in KAU, needs to be more evaluated and assessed to achieve the purpose of this method.

3. Although this survey is assessing the perception of students, we should take it in consideration especially the most significant parament.

\section{Declarattions}

I hereby has no conflict of interest with anyone of my colleagues and this research was conducted after receiving the approval of bioethical committee at the faculty of medicine in king Abdelaziz university and all students who had participated in the study were informed thru completing consent forms

\section{References}

1-Harden RM, Gleeson FA. Assessment of clinical competence using an objective structured clinical examination (OSCE). Med Educ 1979 Jan;13(1):41-54. PubMedPMID:763183.

2-Salwa Alaidarousa, Tarig Awad Mohamed, Emad Masuadic, Siraj Walid Abdullah AlMalkia. Saudi Internal Medicine Residents' Perceptions of the Objective Structured Clinical Examination as a Formative Assessment Tool. Health Professions Education2 (2016)121-129.

3-Zayyan M. Objective structured clinical examination: the assessment of choice. Oman MedJ 2011; 26(4):219-222.

4-Alghamdi K, Katib B, Alhoqail A, Al-khatib T. Perception and acceptance of senior medical students at King Abdulaziz University of the use of Objective Structured Clinical Examination as A tool of assessment. Med Ed Publish /mep.2016.000074.

5-Talal M. Bakhsh, Fachartz, Rashad H. AL kashgari: Running OSCE for a Large Group of Students: Experience of the Surgical Department King Abdulaziz University, Faculty of Medicine.JKAU:Med.Sci,Vol.12,pp. 43-52(2005).

6-Deepti M. Kadeangadi*, Vijaya A. Naik*, M.S. Shivaswamy*, M.D. Mallapur, Objective Structured Clinical Examination; A Tool for Formative Assessment. NJIRM 2014; Vol. 5(1). Jan- Feb.

7- Jason J. Zigmont, PhD,* Liana J. Kappus, MEd,* and Stephanie N. Sudikoff, MD*, †The 3D Model of Debriefing: Defusing, Discovering, and Deepening. . 
8- Rushforth HE. Objective structured clinical examination (OSCE): review of literature and implications for nursing education. Nurse education today. 2007 Jul 1;27(5):481-90

9-Marcyjanik, D.L., Johnson, N.L., 2016. Use of Objective Structured Clinical Examination in a Senior Baccalaureate Nursing Course for Assessment of End-Of-Program Outcomes. file:///C:/Users/user/Downloads/2_Marcyjanik_D_p76719_1.pdf.

10- Obizoba, C., 2018. Mitigating the Challenges of Objective Structured Clinical Examination (OSCE) in Nursing Education: A Phenomenological Research Study. Nurse education today.

11- Shen,L.,Zeng,H.,Jin,X.,Yang,J.,Shang,S.,Zhang,Y.,2018.Aninnovative evaluation in fundamental nursing curriculum for novice nursing students: an observational research.J.Prof.Nurs.34(5),412-416.https://doi.org/10.1016/j.profnurs.2018. 05.002.

12- Massey,D.,Byrne,J.,Higgins,N.,Weeks,B.,Shuker,M.A.,Coyne,E.,Mitchell,M.,

Johnston,A.N.,2017.EnhancingOSCEpreparednesswithvideoexemplarsinundergraduatenursingstudents.Amixedmethodstudy.NurseEduc.Today54,5661. https://www.ncbi.nlm.nih.gov/pubmed/28477564.

13- Solà,M.,Pulpón,A.M.,Morin,V.,Sancho,R.,Clèries,X.,Fabrellas,N.,2017.Towardsthe

implementationofOSCEinundergraduatenursingcurriculum:aqualitativestudy. NurseEduc.Today49,163-167.

\section{Figures}

\begin{tabular}{|l|l|l|l|l|l|l|l|l|l|l|}
\hline & 2014 & 2015 & 2016 & 2017 & 2018 \\
\hline $\mathrm{M}$ & 90 & $43 \%$ & 55 & $35 \%$ & 43 & $29 \%$ & 96 & $44 \%$ & 98 & $43 \%$ \\
\hline $\mathrm{F}$ & 100 & $48 \%$ & 83 & $53 \%$ & 62 & $40 \%$ & 118 & $55 \%$ & 120 & $53 \%$ \\
\hline incomplete & 18 & $8 \%$ & 20 & $12 \%$ & 48 & $31 \%$ & 12 & $1 \%$ & 10 & $4 \%$ \\
\hline Total & 208 & $91 \%$ & 158 & $88 \%$ & 153 & $69 \%$ & 216 & $99 \%$ & 228 & $96 \%$ \\
\hline
\end{tabular}

Figure 1

Summarization of all undergraduate medical students who had participated in the formative (OSCE) to measure their competency and proficiency.

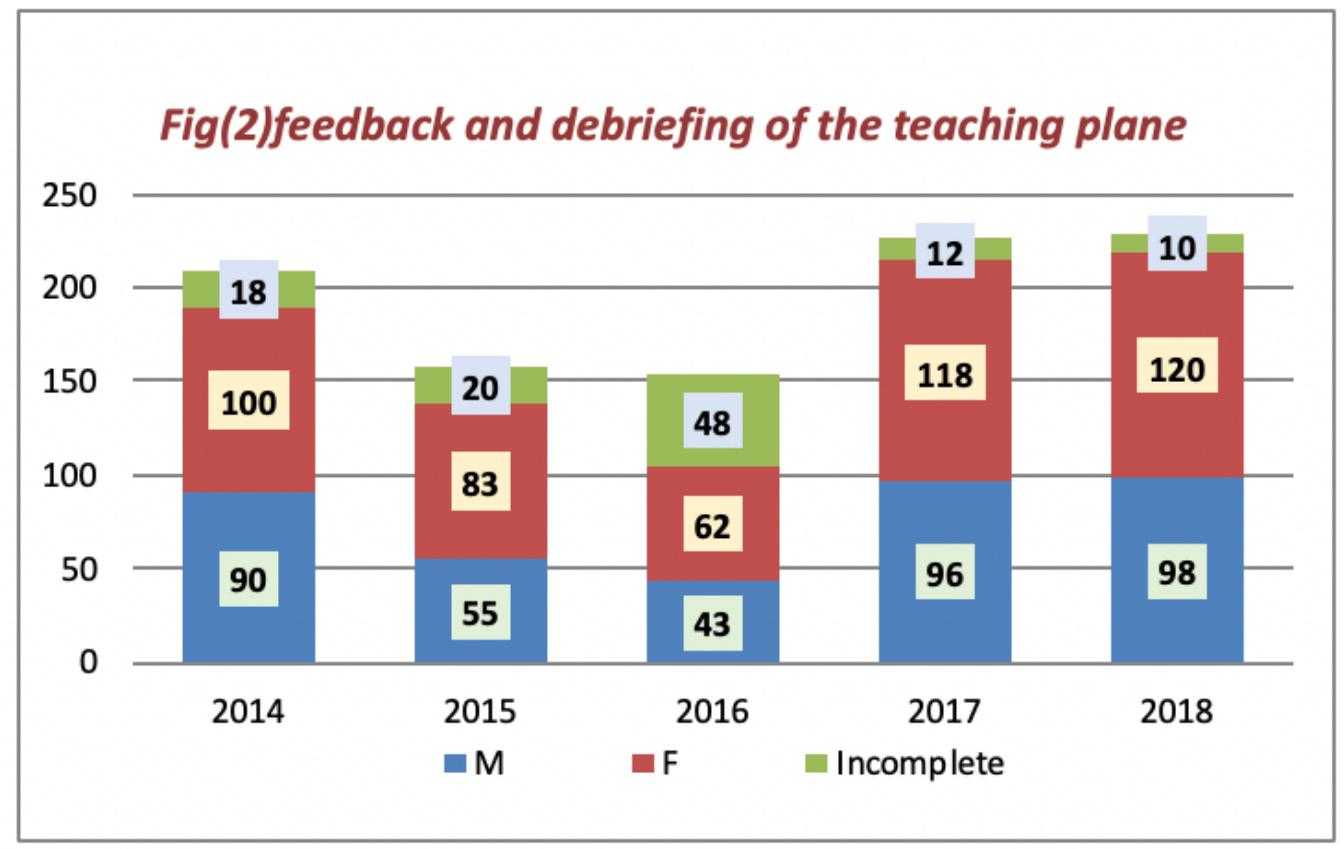

Figure 2

Feedback and debriefing of the teaching plane 


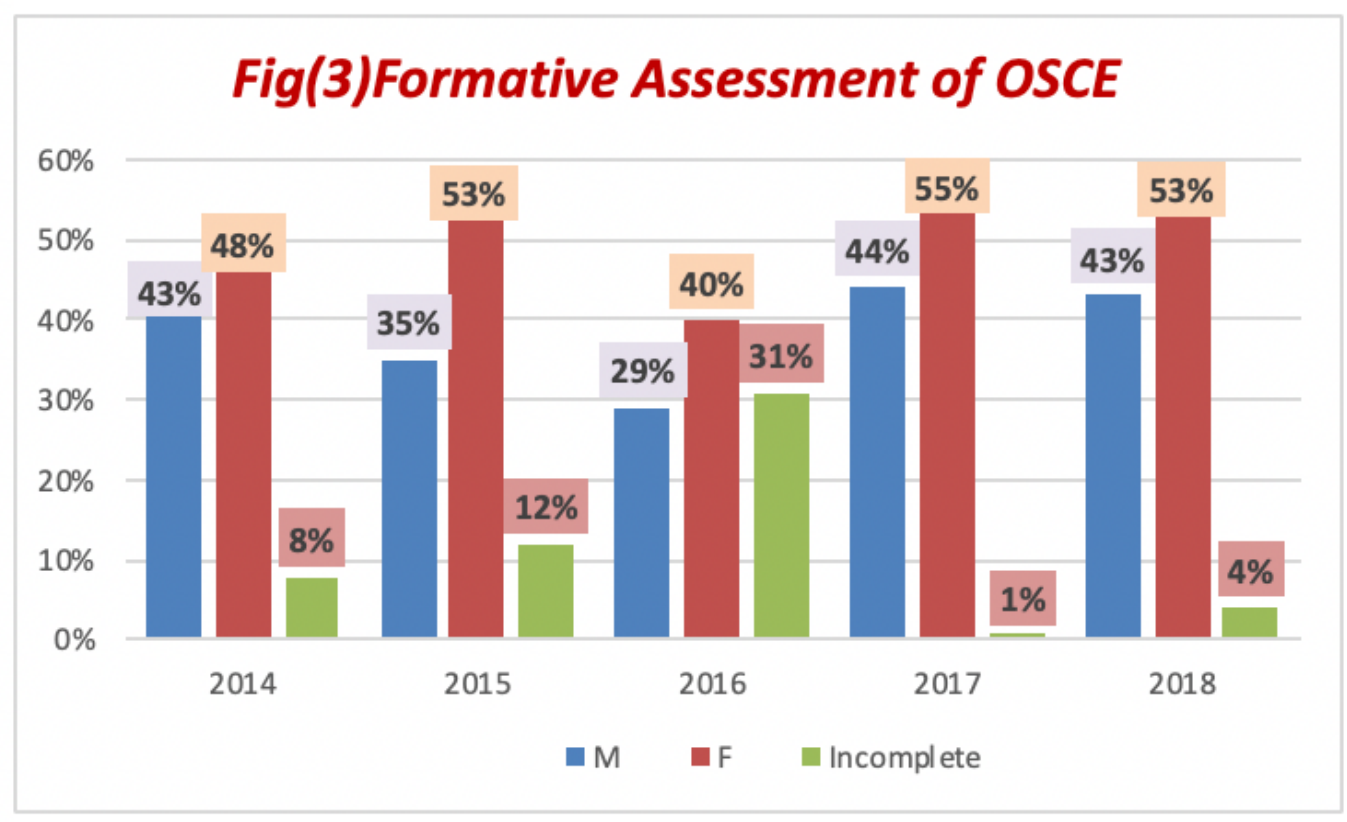

Figure 3

Formative Assessment of OSCE

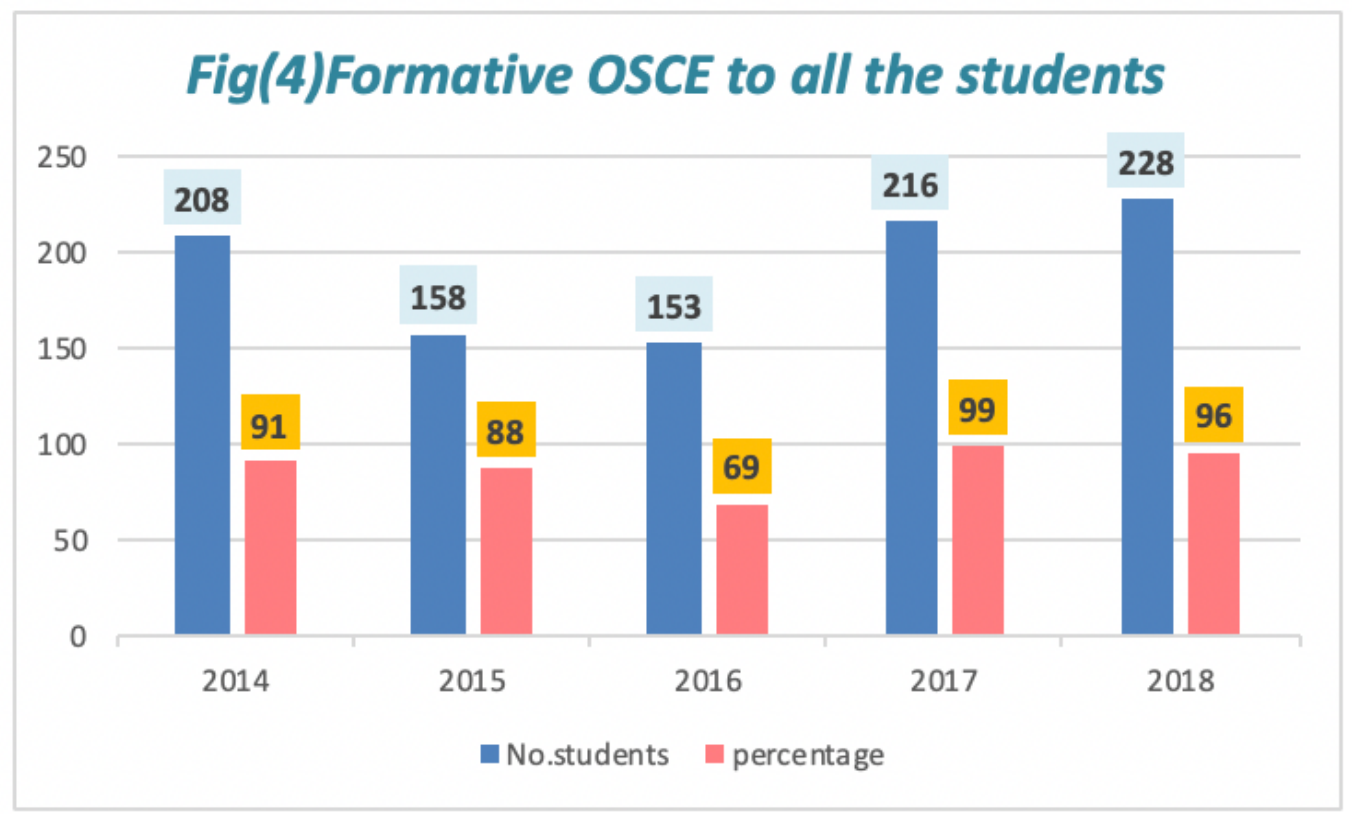

Figure 4

Formative OSCE to all the students 


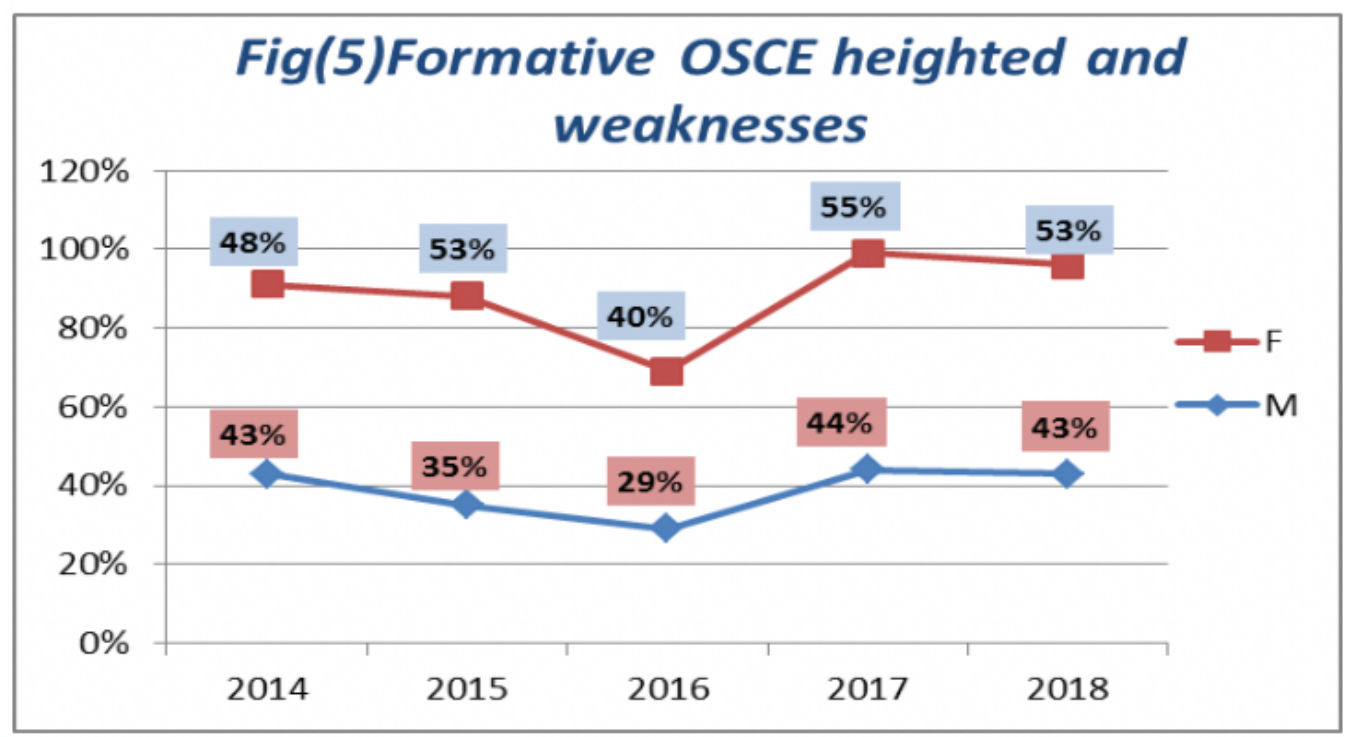

Figure 5

Formative OSCE heighted and weaknesses

\section{Supplementary Files}

This is a list of supplementary files associated with this preprint. Click to download.

- RajaaAllhianiComplete.docx 